\title{
Paraparesia Espástica Tropical en un paciente con HTLV-I
}

Francisco Rosero Solarte

Médico Interno. Facultad Ciencias de la Salud, Universidad Tecnológica de Pereira.

e-mail: franciscomd@hotmail.es

\section{Claudio Aguirre Castañeda}

Neurólogo Clínico. Profesor Asistente, programa de Medicina, Universidad Tecnológica de Pereira.

Dora Luisa Orjuela Zuluaga

Médica Internista. Profesora Asociada, programa de Medicina, Universidad Tecnológica de Pereira

Marcela Rosero Solarte

Médico y Cirujano. Departamento de Medicina Interna, Hospital Universitario San Jorge - Pereira

\section{Resumen}

La paraparesia espástica tropical asociada a Retrovirus Humano T-linfotropico tipo 1 (HLTV-I) es una mielopatia progresiva crónica caracterizada por el compromiso bilateral de la vía piramidal a nivel medular asociada con trastornos del esfínter vesical. La característica neuropatológica principal es la mielitis crónica, que se presenta con lesiones perivasculares, además de infiltración linfocitaria parenquimatosa. En el presente artículo se hace la presentación de un caso de paraparesia espástica tropical y se revisa la patogenia, el diagnóstico y el tratamiento de la misma.

Palabras clave: paraparesia espástica tropical, retrovirus humano T-linfotropico tipo 1

\section{Abstract}

The tropical spastic paraparesis associated to $\mathrm{Hu}$ man T-lymphotropic Retrovirus type 1 (HTLV-1) is a chronic, progressive myelopathy, characterized by bilateral involvement of the pyramidal tract with sphincter disorders. The main neuropathological features are chronic myelitis, perivascular injury, and parenchymal infiltration of the lymphocytes. A case is presented in this article and reviews the pathogeny, diagnosis and treatment of tropical spastic paraparesis.

Keywords: tropical spastic paraparesis, T-lymphotropic Retrovirus type 1

Recibido para publicación: 19-04-2010

Aceptado para publicación: 20-06-2010 


\section{Introducción}

El Retrovirus Humano T-linfotropico tipo 1 (HTLV-I), se descubrió en 1980 por Poiesz y cols en un paciente con linfoma cutáneo de células T. Gessain y cols en 1985, establecieron que el HTLV-I también se encontraba asociado a la Paraparesia Espástica Tropical (PET). A principios de 1986 el HTLV-I se asoció con la Paraparesia Espástica Espinal (SSP) del sur del Japón donde se le dio el nombre de HAM (HTLV-I Associated Myelopathy). En Colombia, el HTLV-I fue detectado en 1981 por Zaninovic y cols, en una serie de pacientes de la población de Tumaco y otras poblaciones de la costa pacífica que eran portadores de una paraparesia espástica progresiva. Como la PET y la HAM son dos síndromes similares, en 1988 la Organización Mundial de la Salud (OMS) recomendó utilizar el nombre (TSP/HAM, PET/MAH) para los dos síndromes. A partir de 1986 la PET/HAM se ha informado en casi todo el mundo (excepto en las regiones ártica y antártica) y en todas las razas de la tierra afectando actualmente a 20 millones de personas.

\section{Caso clínico}

Presentamos el caso de un hombre de 46 años, natural y procedente de Pereira, que consultó por cuadro clínico de dos años de evolución con dificultad progresiva para la marcha, además parestesias en la planta de los pies, dificultad para orinar asociada a retención. Refiere como antecedentes médicos hipertensión arterial en tratamiento. En la revisión por sistemas presenta impotencia sexual desde hace cuatro meses. Al examen físico se encuentra alerta, en aparente buen estado general, orientado en las tres esferas. Signos vitales sin anormalidad. Se evidencia pies en garra. Examen neurológico: consciente, orientado en las tres esferas. No hay deterioro en funciones cognitivas. Pares craneales normales, fondo de ojo normal. Motor: Fuerza de $5 / 5$ en miembros superiores y $3 / 5$ en miembros inferiores. Hipertonia en miembros inferiores para un Asworth de III/V, reflejos simétricos de $++/++++$ en miembros superiores, $\mathrm{y}++++/++++$ en miembros inferiores, clonus aquiliano y patelar bilateral, Babinski bilateral, Hoffman negativo. Sensibilidad superficial, profunda, vibración y propiocepción sin anormalidad. Marcha en tijera debida a la espasticidad. Estos síntomas hallazgos fueron de evolución lenta y progresiva

Datos de laboratorio: Cuadro hemático, TGO, TGP, BUN, Creatinina y otros, normales. En LCR: presión de $14 \mathrm{~cm} / \mathrm{H}_{2} 0$, aspecto de cristal de roca, leucocitos 10 (100\% Linfocitos), proteínas: $65 \mathrm{mg}$, glucorraquia: 60/80 mg, KOH: Negativo, BK: Negativo, Tinta china: Negativa. Serología VDRL: negativa. FTA Abs: No reactivo. Anticuerpos para HTLV-I: Positivo en sangre. VIH: Negativo

Imágenes diagnósticas: La Radiografía de tórax es normal. La Resonancia magnética evidencia clara atrofia de médula dorsal la cual expresa pérdida de axones motores (figura 1).

Figura 1. RM de médula cervico-dorsal. Atrofia de médula dorsal que expresa la pérdida de los axones motores

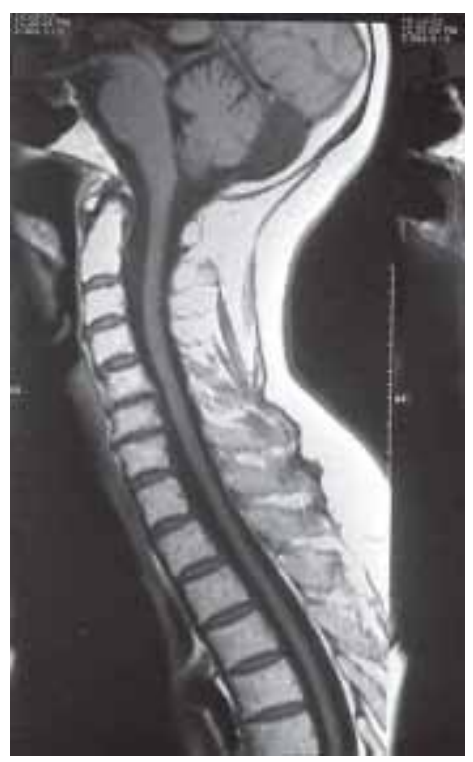

Evolución: El paciente presenta progresiva espasticidad de miembros inferiores de dos años de evolución, con marcha en tijeras; actualmente la paciente requiere de ayudas ortopédicas para caminar, y es la evolución natural de esta patología hasta quedar en silla de ruedas. Además, la espasticidad se ha manejado con baclofeno 25 mg cada 8 horas $25 \mathrm{mg}$ cada 8 horas $25 \mathrm{mg}$ cada 8 horas $25 \mathrm{mg}$ cada 8 horas y terapia física. 


\section{Discusión}

Se trata de un paciente de género masculino que presentó cuadro progresivo de dificultad para la marcha, debido a debilidad progresiva de miembros inferiores, concomitante con hipertonía, hiporeflexia, disfunción sexual e incontinencia urinaria; síntomas que han aumentado de forma paulatina e insidiosa, actualmente sólo puede caminar con ayudas ortopédicas y, finalmente se hace diagnóstico de PET con paraclinicos confirmatorios de HTLV1.

Trasmisión: El retrovirus HTLV-1 causante de la PET/ HAM se trasmite por medio de linfocitos infectados. El principal medio de trasmisión en zonas endémicas es de contagio sexual, también se encuentra la trasfusión de sangre infectada, la trasmisión perinatal a través de la lactancia materna, últimamente se ha reportado el contagio por el trasplante de órganos, además de la utilización de agujas infectadas entre drogadictos.

Manifestaciones clínicas: La PET es la manifestación más común de la infección por HTLV1 , aproximadamente el $2.4 \%$ de personas infectadas por este virus desarrollan esta polineuropatía. Usualmente se presenta después de los 40 años, aunque se han reportado en personas desde los 20 años. Típicamente comienza de forma lenta, progresiva e insidiosa, produciendo debilidad, rigidez de miembros inferiores en el $60 \%$ de los casos, aunque se conserva la fuerza de miembros superiores. Es usual encontrar dolor lumbar, hipoestesia generalizada y ardor en las plantes de los pies. Durante el curso de la enfermedad, es muy común la impotencia sexual, la disfunción de la vejiga con aumento en la frecuencia urinaria, la urgencia miccional además de incontinencia o retención. En algunos casos los síntomas urinarios anteceden la paraparesia por muchos años. Los estudios urodinámicos revelan una vejiga hiperactiva, aunque algunos individuos muestran baja actividad o atonía de la vejiga. Con la progresión de los síntomas aparece una marcha espástica que puede llegar a ser incapacitarte, hasta que finalmente un tercio de los pacientes termina en una silla de ruedas: cerca de la mitad requieren prótesis para deambular. En un estudio reciente de Franzoi y cols encontraron que los aspectos más comunes de discapacidad están en la marcha y áreas de control del esfínter.

La PET/HAM progresa más rápidamente en mujeres que en hombres. Esta diferencia es particularmente más notable en las mujeres cuya enfermedad comenzó antes de la menopausia que en la mujeres en la cuales la enfermedad se presenta después de la menopausia. No se sabe la razón de este fenómeno, pero es posible que el género y las hormonas jueguen un papel en el desarrollo de esta patología. Además del género, la carga viral es otro factor que influye de forma importante en la evolución de la enfermedad. Esto se demuestra en la rápida progresión de la PET de pacientes con carga viral alta con respecto a pacientes con carga viral baja, posiblemente indicando un aumento de la proliferación o la migración de linfocitos infectados por HTLV-1.

En la exploración neurológica se suele encontrar marcha espástica, y en algunos casos se evidencia paraplejía debido a la debilidad muscular de miembros inferiores y cadera, con aumento en el tono muscular de estos miembros. De igual forma se encuentra hiperreflexia patelar, clonus y reflejo de babinski positivo de forma bilateral. Puede haber compromiso de la sensibilidad evidenciado en hipoestesia a la vibración en tobillos y dedos de los pies.

Ayudas diagnósticas: En el liquido cefalorraquídeo (LCR) se puede evidenciar pleocitocis moderada con predominio linfocitario y en algunos casos linfocitos $\mathrm{T}$ atípicos, de núcleos multisegmentados (células en flor), las cuales también se encuentran en frotis de sangre periférica; en LCR se encuentra también aumento de proteínas, IgG y presencia de bandas oligoclonales debido a la producción intratecal de anticuerpos anti HTLV-1. Se encuentran títulos positivos de anticuerpos anti-HLTV-1en LCR y en suero.

La resonancia magnética es el método imagenológico de más ayuda para el diagnóstico de esta patología, en el $50 \%$ a $80 \%$ de los pacientes se encuentran focos hiperintensos no especificados en áreas periventriculares y subcorticales. En el comienzo de la enfermedad se evidencia edema localizado en los segmentos torácicos y lumbares de la médula 
espinal; ya cuando la enfermedad progresa a estadios avanzados se encuentra atrofia en los segmentos torácicos.

Los hallazgos histopatológicos demuestran inflamación crónica difusa con manguitos perivasculares de linfocitos y células mononucleares, acompañada de pérdida folicular crónica de mielina y axones a nivel de haces piramidales y fascículo grácilis en los cordones posteriores

Si bien la PET/HAM junto con la leucemia/linfoma de células T del adulto son los principales síndromes de esta enfermedad, existen otras patologías asociadas con manifestaciones oftalmológicas, reumatológicas, dermatológicas, sistémicas, y otras formas de compromiso neurológico (tabla1).

Tabla 1. Patologías asociadas al retrovirus HTLV1, adaptado del original de Román GC.

\begin{tabular}{|c|c|}
\hline Principales síndromes & $\begin{array}{l}\text {-Paraparesia espástica tropical asociada a HLTV1 } \\
\text {-Leucemia/linfoma del adulto de células T }\end{array}$ \\
\hline Otras manifestaciones neurológicas & $\begin{array}{l}\text {-Mielitis aguda rápidamente progresiva } \\
\text {-Síndrome Espinocerebeloso } \\
\text {-Enfermedad motoneuronal por HLTV-1 } \\
\text {-Leptomeningitis neoplásica } \\
\text {-Paquimeningitis hipertrófica crónica } \\
\text {-Miopatías por HLTV-1 } \\
\text { • Polimiositis y miopatía por cuerpos de inclusión } \\
\text {-Polineuropatías por HLTV-1 } \\
\text { - Neuropatía distal axonal sensitivo motora } \\
\text { - Disautonomía simpática } \\
\text { - Padiculopatía lumbosacra } \\
\text { - Neuritis óptica } \\
\text {-Déficit cognitivo } \\
\text { - Demencia subcortical }\end{array}$ \\
\hline Manifestaciones oftalmológicas & $\begin{array}{l}\text {-Queratoconjuntivitis seca } \\
\text {-Queratitis crónica intersticial } \\
\text {-Atrofia del nervio óptico } \\
\text {-Uveítis } \\
\text {-Epiescleritis } \\
\text {-Coroiditis degenerativa }\end{array}$ \\
\hline Manifestaciones reumatológicas & $\begin{array}{l}\text {-Síndrome pseudo-Sjogren } \\
\text {-Lumbalgias atípicas }\end{array}$ \\
\hline Manifestaciones dermatológicas & $\begin{array}{l}\text {-Xerosis, hipohidrosis } \\
\text {-Dermatitis crónica }\end{array}$ \\
\hline Otras manifestaciones sistémicas & $\begin{array}{l}\text {-Alveolitis pulmonar linfocítica } \\
\text {-Cistitis y prostatitis crónicas } \\
\text {-Estrongiloidiasis } \\
\text {-Tiroiditis }\end{array}$ \\
\hline
\end{tabular}

Tratamiento: No existe un tratamiento específico para la infección por el virus HTLV-1. Hasta la fecha, numerosos enfoques terapéuticos se han presentado para el tratamiento de la PET/HAM, de los cuales ninguno logra detener la progresión de la enfermedad. Sin embargo, la terapia inmunomoduladora y la terapia antiviral han demostrado una mejoría a corto plazo. Los que ofrecen mayor expectativa son los tratamientos con inmunomoduladores para el manejo de la condición inflamatoria crónica: en primer lugar, por medio de la supresión de la activación inmunitaria, en particular para las células infectadas por HTLV-1 y, en segundo lugar, por la inhibición de la transmigración de estas células de la médula espinal, y finalmente por la reducción de la inflamación crónica en la médula espinal, a través de la baja regulación de citoquinas inflamatorias y/o la expresión de moléculas 
de adhesión. Por falta de una estrategia terapéutica óptima para esta enfermedad neurológica progresiva, el tratamiento sintomático es de gran importancia, incluyendo fisioterapia y rehabilitación, medicamentos contra la espasticidad, manejo de problemas urinarios y estreñimiento, de igual forma una adecuada prevención de infecciones urinarias y úlceras por decúbito (tabla 2).

Tabla 2. Tratamientos ensayados en pacientes con PET/HAM, adaptado del original de Tatsufumi Nakamura (2009).

\begin{tabular}{|c|c|}
\hline \multicolumn{2}{|r|}{ Terapias centradas en efectos inmunomoduladores } \\
\hline $\begin{array}{c}\text { Efectos: } \\
\qquad \\
- \\
- \\
-\end{array}$ & $\begin{array}{l}\text { Supresión de la activación inmunitaria, en particular para las células infectadas por HLTV- } \\
1 \text { activa } \\
\text { La inhibición de la transmigración de HTLV-I-activa de las células infectadas a la médula espinal } \\
\text { La reducción de la inflamación crónica de la médula espinal }\end{array}$ \\
\hline 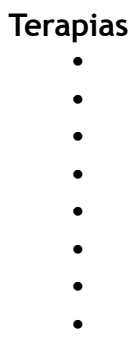 & $\begin{array}{l}\text { Hormonas corticosteroides } \\
\text { Purificación de la sangre } \\
\text { La pentoxifilina } \\
\text { Heparina } \\
\text { Altas dosis de gammaglobulina intravenosa } \\
\text { Altas dosis intermitentes de vitamina C } \\
\text { Fosfomicina y la Eritromicina } \\
\text { Beber leche fermentada }\end{array}$ \\
\hline \multicolumn{2}{|r|}{ Terapias centradas en efectos antivirales } \\
\hline $\begin{array}{c}\text { Efectos: } \\
\stackrel{\bullet}{\bullet} \\
\bullet\end{array}$ & $\begin{array}{l}\text { Supresión de la expresión y/o replicación de HTLV-I } \\
\text { La inhibición de la proliferación de HTLV-I de células infectadas } \\
\text { La eliminación de HTLV-I de células infectadas }\end{array}$ \\
\hline $\begin{array}{c}\text { Terapias } \\
\stackrel{\bullet}{\bullet} \\
\cdot \\
\cdot\end{array}$ & $\begin{array}{l}\text { Interferón-a y } B \\
\text { Inhibidores de transcriptasa inversa } \\
\text { Anticuerpo anti-Tac humanizado } \\
\text { Inhibidor de la enzima histona deacetilasa }\end{array}$ \\
\hline
\end{tabular}

\section{Conclusión}

Estamos ante un caso de una patología que se creía inicialmente por epidemiología, sólo se presentaba en la población de raza negra (Colombia, encontrándose de forma endémica en la costa pacífica de Nariño, Cauca y Valle del Cauca), pero con el paso de los años, el paso de las fronteras y la multipluralidad interracial, se presenta en cualquier raza. Esta patología desafortunadamente no es fácil diagnosticarla tempranamente, usualmente no se sospecha por presentarse de forma poco frecuente y por desconocimiento del personal médico de la misma, y la posibilidad de tratamiento es limitada y nos limitamos al manejo sintomático. Por lo tanto, al ser una enfermedad prevenible por sus vías de transmisión, es en este aspecto donde se debe trabajar más. 


\section{Bibliografía}

1. Araujo A, Silva M. The HTLV-1 neurological complex. Lancet Neurol, 2006; 5: 1068-76

2. Cartier RL. Paraparesia espástica progresiva asociada a HTLV-I en Chile: Estudio y seguimiento de 121 pacientes por diez años. Rev Chilena Neuro-psiquiatria, 2009; 47(1): 50-66

3. Nakamura T. HTLV-I-associated myelopathy/tropical spastic paraparesis (HAM/TSP): the role of HTLV-I-infected Th1 cells in the pathogenesis, and therapeutic strategy. Folia Neuropathol, 2009; 47(2): 182-194

4. Nakamura T, Nishiura Y, Eguchi K. Therapeutic strategies in HTLV1 associated myelopathy/tropical spastic paraparesis (HAM/TSP). Central Nervous System Agents in Medicinal Chemistry, 2009; 9: 137-149.

5. Olindo S, Lézin A, Stéphane O. HTLV-1 proviral load in peripheral blood mononuclear cells quantified in 100 HAM/TSP patients: A marker of disease progression. Journal of the Neurological Sciences, 2005; 237(12): 53-59

6. Roman GC. Treatment of human T lymphotropic virus type 1, infections of nervous system. En, Noseworthy JH, Neurological Therapeutics: principles and practice. Oxford: Informa health care. Second edition, 2006; 87: 1074-1081.

7. Román GC, Navarro LI. Aspectos neurológicos de la infección por el retrovirus humano HTLV-1. En: Neurología, 7 Ed: Corporación para Investigaciones Biológicas 2010: 347-352

8. Roman GC, Navarro LN. The discovery of HTLV-1 myelitis: 21 years later. Lancet Neurol, 2007; 6:104-105

9. Szczypinska E, Wallace M. Human T-Cell Lymphotrophic Viruses, En http://emedicine.medscape.com/ article/219285-overview. Nov 19, 2009

10. Zaninovic V, Moreno D. A propósito de 5 casos de paraparesia espástica tropical en Puerto Tejada (Cauca). Colombia Médica, 1997; 28: 67-70 